\title{
Circular Economy Potential in the Carpet Industry
}

\author{
Henning Wilts*, Jana Nicolas, Monika Wirges and Klaus Wiesen
}

Wuppertal Institute for Climate, Environment, Energy, Doppersberg 19, 42113 Wuppertal, Germany

\begin{abstract}
The circular economy approach implies significant different potentials, hurdles and barriers according to different industries and products - so far without systematically taking into account differences between sectors. This paper takes the example of the carpet industry that due to its so far low material recycling rates and resource intensity is highly interesting with regard to further promote and strengthen circular economy activities and outlining barriers as well as approaches for overcoming these. Focussing on the EU market, it analyses current material flows including end-of-life (EoL) treatment patterns as well as existing policy frameworks. In this paper three scenarios of carpet production are compared with regard to the material footprints: a nylon carpet with $100 \%$ virgin fibres, another nylon carpet with $50 \%$ virgin and $50 \%$ recycled fibres and a third carpet made from $100 \%$ recycled fibres. Considering the economic and environmental potentials of circular alternatives, the paper argues that focussing on increased recycling rates alone will not be beneficial but could rather lead to higher environmental burdens, if no significant design changes take place. Such changes need furthermore be accompanied by altered policy frameworks in order to make a circular carpet industry a viable option. These conclusions are based on analyses of the regulatory framework and treatment patterns and an environmental impact analysis of primary and secondary carpets.
\end{abstract}

Keywords: Carpet; Circular economy; Eco design; Material footprint; Recycling; Reuse

\section{Introduction}

The circular economy concept is high on the political agenda; especially the European Commission with its Circular Economy Action Plan [1] has set ambitious targets for the EU member states and aims to overcome traditional linear patterns of production and consumption characterized as "produce-use-dispose" approach. The circular economy is a concept, where products are not just used once and discarded but are reused, recycled and returned back to the economy with a new life. Numerous studies (e.g., Bastein et. al 2013) have highlighted not only environmental but also economic benefits from moving from a linear to a circular economy. E.g., according to the Ellen MacArthur Foundation (2015), Europe could create up to 3 million local jobs and cut its CO2 emissions by $48 \%$ by 2030 , if it moved to truly a circular economy.

These impressive figures raise the question of impacts on specific industry sectors. The starting point of the above mentioned EU Circular Economy Action Plan is a selection of priority waste streams, not of industries. The European Commission's scoping study [2] identified priority materials (agricultural products and waste, wood and paper, plastics, metals and phosphorus) and priority sectors (packaging, food, electronic and electrical equipment, transport, furniture, buildings and construction). The Ellen MacArthur Foundation identifies the highest potential for circularity in complex medium-lived products such as (mobile) phones or washing machines. For most other sectors circular economy potentials are still unclear and these uncertainties often hinder necessary investments into new circular business models and adopted waste infrastructures [3].

Against this background, this paper takes the example of the carpet industry that due to its so far low material recycling rates and resource intensity is highly interesting with regard to further promoting and strengthening circular economy activities and outlining barriers as well as approaches for overcoming these. Focussing on the EU market, it analyses current material flows including end-of-life treatment patterns as well as existing policy frameworks and the incentives provided by these regulations. Focussing on the economic and environmental potentials of circular alternatives, the paper highlights that significant design changes will be necessary in order to make a circular carpet industry a viable option.

The paper is structured as follows: Chapter 2 describes the methodological approach and empirical basis, chapter 3 analyses the regulatory framework and treatment patterns. Based on out these outcomes, chapter 4 presents an environmental impact analysis of primary and secondary carpets based on which chapter 5 discusses the results and presents conclusions as well as the need for further research.

\section{Methodological Approach and Empirical Basis}

The paper is based on a value chain analysis according to Porter [4]. It takes into account governance aspects by an analysis of the regulatory framework as well as market aspects for economic actors for which semi-structured expert interviews with relevant business associations and front-runner companies in terms of new carpet design have been conducted. It also takes into account carpet production techniques and post-consumer treatment methods. Besides the mentioned interviews the research base consists of literature research as well as statistics, and company website claims in order to analyse the current market structures and developments.

For the environmental assessment, the paper uses the concept of Material Footprint Indicators: The raw material use is measured by the Material Footprint [5]. The Material Footprint is an indicator based on the concept Material Input per Service Unit (MIPS), also known as Ecological Backpack. The Material Footprint is an aggregated indicator that accounts for all abiotic and biotic raw materials from nature

*Corresponding author: Henning W, Wuppertal Institute for Climate, Environment Energy, Döppersberg 19, 42113 Wuppertal, Germany, Tel: 020224920; Fax: 02022492138; E-mail: henning.wilts@wupperinst.org

Received November 23, 2017; Accepted November 25, 2017; Published December 02, 2017

Citation: Wilts H, Nicolas J, Wirges M, Wiesen K (2017) Circular Economy Potential in the Carpet Industry. J Glob Econ 5: 271. doi: 10.4172/2375-4389.1000271

Copyright: (c) 2017 Wilts $\mathrm{H}$, et al. This is an open-access article distributed under the terms of the Creative Commons Attribution License, which permits unrestricted use, distribution, and reproduction in any medium, provided the original author and source are credited. 
required for all lifecycle phases from production to disposal (cradleto-grave) including materials from unused extraction that have no economic use such as soil excavation and tailings.

\section{Market and Regulatory Framework Conditions for Carpets}

So far the carpet industry is dominated by a linear concept of production and usage: In Europe, about $60 \%$ are sent to landfills [6] and another large share is incinerated. Specific recycling rates for carpets are not available but e.g., for the UK current recycling rates are estimated at only around 5\%, with reuse rates negligible [7]. Against this background, a call for higher or product specific recycling rates would initially seem logical. The specific purpose of this paper is to highlight the challenges to increase circularity without significant changes in the design of products. Every attempt to increase circularity in this sector will require an improved understanding of the existing incentive structures that are caused by the interaction of demand and supply structures and the current regulatory framework.

\section{Demand structure}

The global carpet market has steadily increased over the last decades: According to a study of The Freedonia Inc., the global demand for carpets and rugs totalled over 4.45 billion square meters in 2014 . It is forecast to rise $3.8 \%$ annually and reach 5.4 billion square meters in 2019 [8]. The demand of carpet can be divided into the following three markets: residential buildings, non-residential buildings, and transportation equipment and other. Non-residential buildings are e.g., offices, institutional, industrial and other types of business and government buildings. Even though the demand varies according to the different countries and regions, in general, the residential sector is the largest, followed by the non-residential sector and to a much lesser extent the transportation equipment sector. In 2013 residential buildings accounted for $57 \%$ of the total global flooring and carpet demand whilst non-residential buildings accounted for 37\% [9].

Currently, tufted carpets cover the largest share of the global market with $52.3 \%$ of the demand, weaved carpets $(26.1 \%)$, knotted carpets (7.1\%) and long narrow carpets and other carpets (14.5\%) cover the remaining share (Global Research \& Data Services (n. u.), 2014). The general lifespan of a carpet is about 7 to 20 years; depending on the material, the density of pile, carpet design and use intensity, excluding factors like damage, change of taste or change of the facility's owner or usage [10].

\section{Supply}

The production of carpets is concentrated in relatively few countries. The USA is leading with over $45 \%$ of the world's carpet and rugs demand produced in Georgia alone [11]. Belgium is the second largest supply market and is a large exporter, as the demand for carpets in Belgium is relatively low compared to its production and other countries like the USA, UK or Germany [10]. In terms of world flooring and carpet market share (total of US\$ 230 in 2013) the US based Mohawk Industries was the world's largest floorcovering producer in 2013 (US $\$ .1$ billion, 3.1\% of the world's market), followed by US based Shaw Industries (US\$ 3.8 billion, $1.7 \%$ of the world's flooring market in 2013), which is the largest manufacturer if it comes to carpets alone. The third largest producer of floorcoverings in 2013 was the French company Tarkett (US\$ 2.9 billion, $1.3 \%$ of the world's flooring market).

\section{Regulatory frameworks}

With regard to the policy framework the use of carpets in private, commercial as well as public buildings like every other product is regulated by a variety of policy frameworks and linked to a large number of technical regulations e.g., regarding specific substances, fire protection or quality standards for the installation in areas with a high number of visitors (e.g., BREEAM, LEED etc.). Nevertheless, there are hardly any specific policies or regulations specifically targeting sustainable or specifically circular practices for carpets in buildings. Besides this, several broader frameworks also include carpets although not directly mentioned. For example, the EU Communication on Resource Efficiency Opportunities in the Building Sector promotes the use of recycled materials or the re-use of existing and waste materials in order to divert them from being landfilled.

Also, the regulatory framework for end-of-life treatment of carpets is heterogeneous and doesn't set clear incentives: Depending on the specific type of usage, carpets can end their lives as very different categories of waste with different treatment and recycling requirements. If carpet has been used in private buildings and has been removed separately it becomes residual waste. Discarded carpets can also be classified as commercial waste (coming from commercial buildings) or dominantly as deconstruction waste. Especially for the deconstruction phase of buildings, it has to be emphasised that no regulations exist that would require the removal of carpets before the buildings are torn down. Together with other building materials, the carpets get shredded crushed and sorted so that most of the carpets end up in the sorting residues that is either landfilled or incinerated.

Policy initiatives to support more circular solutions so far struggle: E.g., California (the so to say carped hub in the US in terms of carpet production) implemented the California Carpet Stewardship Programme (Law AB 2398) that obligates everyone who sells carpet in California to add a stewardship assessment fee which started at $\$ 0.05$ rose to $\$ 0.25$ per square yard from January 1 st, 2017 in order to offset negative market developments [12]. This fee results into a fund which shall be used to increase carpet reuse and recycling activities, to improve carpet recyclability and also promote the use of secondary products made from post-consumer carpet [13]. Nevertheless efforts to date have not resulted in a demonstration of continuous meaningful improvements; in fact, the recycled output rate dropped from 12 percent in 2014 to 10 percent in 2015 [14].

\section{Economic drivers for carpet recycling}

The current focus on linear solutions is especially caused by a lack of economic drivers for carpet recycling; mainly due to the complexity of the product and the wide variety of materials that are bonded together in most carpets: mixing various polymers, latex adhesives and filler materials such as chalk and bitumen. A carpet usually consists of three layers: the face fibre (sometimes called the 'pile' - which is on top), a primary backing (which the fibre is connected to, often using latex glue) and the secondary backing, the material that provides a cushion and gives the carpet greater dimensional stability and strength. The primary and the secondary backing are usually glued together (again using latex) and the secondary backing might contain fillers such as chalk and bitumen.

At present, it is thought that only Nylon 6 is being recycled back into fibre for carpets (e.g., from old fishing nets like at Aquafil, an Italian producer of nylon 6 fibres from materials such as fishing nets, postconsumer carpets and post-production yarn waste) and that there are no plants processing post-consumer carpet made of Nylon 6.6 or other polymers to make yarn fibres. All other carpets made with PP, PET or mixed fibres are down-cycled, e.g., into equestrian surfaces and low- 
grade plastics, or used for energy recovery or sent to landfill. Parts are down-cycled into mixed fabric backings for carpets. But it is important to note that shredding different material types, mixing them and then using these mixed materials again (even if in a similar product) is not to be seen as recycling but as down-cycling. The different materials cannot be separated again and their quality and value decreases. Mixed carpets with more than one face fibre type hold an additional challenge as most types of plastic are not compatible in the recycling process and even small amounts of one type entering the recycling process of another type could contaminate and hence ruin the whole recycling process [15]. Similarly to carpet face fibres, carpet backings (a mix of polymers such as PET, chalk and latex or bitumen) are also down-cycled at best, incinerated for energy recovery or landfilled. This is due to the economics of the situation (treatment cost versus low virgin material prices) and the problem with the colourisation of PET materials. Nylon 6 and nylon 6.6 (Polyamide 6.6 / PA 6.6) that are used as face fibre are technically recyclable but due to the mixture of materials - especially with PET - these processes are not economically feasible. A similar situation is at the moment also true for pure material carpets, e.g., pure polypropylene carpets, in Europe [10]. A dramatic increase in oil prices is seen as a main prerequisite setting additional incentives to focus on recycled materials and to adopt production systems accordingly.

Also, the current use patterns decrease the economic feasibility of carpet recycling: Bonding broadloom carpets and carpet tiles securely to a building's floor can lead to damage of the product or contamination of the materials (e.g., with glue). During renovation carpet and if the carpet is only removed after renovation, its recyclability can be effectively destroyed by plaster and paint splashes and can be exposed to high amounts of dust. Collective disposal with other materials, on the other hand, leads to carpets getting mixed with other materials (e.g., demolition waste and plastics) becoming unsuitable for recycling, as either the sorting cost will further increase or the material recycling is technically not possible anymore. Especially the handling, identification and sorting of the carpets face fibres is a highly manual (due to different shapes and sizes of the carpets, contamination etc.) and hence costly.

\section{Raw Material Savings by Carpet Recycling}

As outlined above there obviously is a potential to increase the relevance of carpet recycling - if the described barriers could be overcome e.g., by a strictly implemented and monitored extended producer responsibility scheme for carpets. Outcomes of a research project in Germany (Recycling of Carpet Materials - RECAM) indicate a potential collectable amount of end-of-life carpets of $5 \mathrm{~kg}$ per capita and year that could be recycled [16].

Against this background, the purpose of the following analysis is to estimate the amount of raw materials saved by closed-loop recycling of residential carpets compared to final disposal. For this paper, a nylon broadloom carpet was considered. The nylon broadloom carpet was chosen due to the fact that so far no PET face fibre carpets have been recycled back into PET carpet face fibre, even though the PET carpets gained significant market share all over the world and is in parts already out-running nylon broadloom carpets, especially in the USA, which has the largest demand for broadloom carpet [17]. The underlying data for the environmental assessment in this paper was taken from the life cycle database Ecoinvent [18]. In this database, the data for plastic represents the European market. Data for the production of some primary plastic fibres (nylon 6.6, polyester and PP) were taken from the European Life Cycle Database (ELCD) [19]. However, the data in the Ecoinvent database, as well as the data in the ELCD database, are only given in an aggregated form. They do not provide information on specific materials used and detailed data on the energy consumption.

\section{System boundaries and functional unit}

To get insights on the Material Footprint of a carpet made of primary nylon fibres in comparison to a carpet made of recycled nylon fibres three scenarios were used:

1. $100 \%$ primary nylon fibres used for the carpet production with $100 \%$ going to landfill at the end-of-life

2. 50\% primary nylon fibres and $50 \%$ recycled nylon fibres used for the carpet production with 50\% going to landfill at the end-of-life

3. $100 \%$ recycled nylon fibres are used for the carpet production, no fibres going to landfill.

In the base case scenario (1), all carpet inputs are from primary material, whereas in (2) and (3) nylon fibres are used which originate from closed-loop recycling of old carpets. Other materials like the backing material as well as energy demand for these and their production processes are assumed to be the same in all scenarios. Figure 1 shows the system boundaries for the analysed scenarios. The

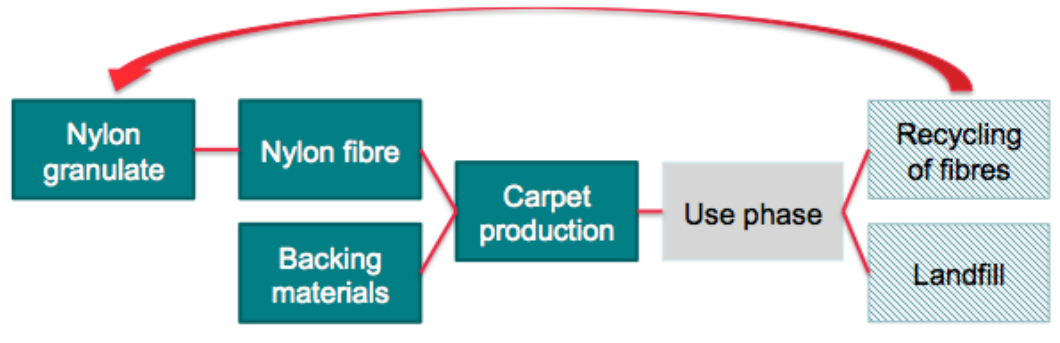

Note:

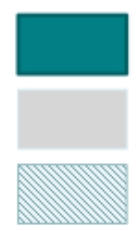

Analysed within the study

Ommitted as assumed to be identical for all systems

Considered depending on the chosen scenario

Figure 1: System boundaries of the considered carpet scenarios (own illustration). 
functional unit - for which the need of natural raw materials in $\mathrm{kg}$ has been calculated - has been defined as $\mathrm{m} 2$ of carpet.

\section{Inventory analysis}

The estimation of raw material savings is differentiated into the production phase, use phase, and end-of-life (disposal and recycling). In order to calculate the production of a carpet, the material and energy demand of a nylon broadloom carpet given in Mahalle [20] was selected, which is based on a Life Cycle Analysis of a generic nylon carpet [21]. The inventory used is given in the following table. A comparison with the Life Cycle Analysis data of floor coverings from Klinger and Savi [22] show, however, which the data differ significantly - especially regarding the energy demand. In the analysis of the generic nylon carpet [21] heating steam is part of the process while in the data from Klinger and Savi [22] most of the energy demand is given as electric energy. Table 1 shows the inventory data for the production of a carpet used for the analysis of this paper.

\section{Use phase}

The energy consumption in the use phase, e.g., due to cleaning the carpet, was omitted as it was assumed the same for carpets made from primary materials and carpets made from recycling materials.

\section{End-of-life (EoL)}

There are different approaches to consider a product's end-of-life in Life-Cycle-Assessment (LCA). For this study the "100:0" approach was used: Whenever a product leaves the system boundaries by recycling, its further processing (e.g., transports, recycling process) is shifted to the product system using the recycled products. Alternatively, the LCA framework allows the attribution of possible partial (50:50) or full benefits (100:0) resulting from the use of the recycled material in other systems to the providing system (e.g., by reuse in other products), which is known as avoided burden approach.

The chosen 100:0 approach urges producers to use a higher share

\begin{tabular}{|l|c|c|}
\hline Input & $\begin{array}{c}\text { Amount per } \mathbf{~ m}^{\mathbf{2}} \text { carpet } \\
{[\mathbf{2 0 , 2 1 ]}}\end{array}$ & $\begin{array}{c}\text { Amount per } \mathbf{~}^{\mathbf{2}} \\
\text { carpet [22] }\end{array}$ \\
\hline Nylon & $1.02 \mathrm{~kg}($ Nylon 6.6) & $0.84 \mathrm{~kg}($ Nylon 6) \\
\hline Polypropylene & $0.23 \mathrm{~kg}$ & $0.09 \mathrm{~kg}$ \\
\hline Polyester & - & $0.09 \mathrm{~kg}$ \\
\hline Styrene butadiene latex & $0.26 \mathrm{~kg}$ & $0.55 \mathrm{~kg}$ \\
\hline Limestone filler & $0.91 \mathrm{~kg}$ & $0.41 \mathrm{~kg}$ \\
\hline Stainblocker & $0.24 \mathrm{~g}$ & - \\
\hline Al(OH)3 & - & $0.14 \mathrm{kk}$ \\
\hline Other additives & $2.00 \mathrm{~g}$ & - \\
\hline Water & $0.96 \mathrm{I}$ & - \\
\hline Electricity & $0.11 \mathrm{kWh}$ & $1.05 \mathrm{kWh}$ \\
\hline Fuel oil & $3.50 \mathrm{MJ}$ & $0.42 \mathrm{MJ}$ \\
\hline Heating steam & $0.72 \mathrm{~kg}$ & - \\
\hline
\end{tabular}

Table 1: Inventory data for the production of a carpet. of secondary material in their products or - even better - to reduce the overall material use. Furthermore, the full consideration of secondary material ensures that only the de facto realised recycling is taken into consideration and not - like in the avoided burden method - the potential recyclability. Table 2 shows an overview of how end-of-life is considered for the 100:0 approach.

\section{Landfill}

For the disposal scenario, it is assumed that all materials of the carpets will go to a landfill, as this is still the most common treatment for carpets in Europe.

\section{Recycling}

According to US EPA [23], per 1,000 kg of old carpet material, less than $50 \%(493 \mathrm{~kg})$ can be recycled. Due to the mostly unrecyclable (not counting down-cycling) carpet backings and the contamination with dust carpet taken out after a refurbishment can contain up to 400 $\mathrm{g}$ of dust per $1 \mathrm{~kg}$ of carpet [24] and other substances, the collectable mass does not equal the recyclable mass. In addition this high share of dust need to be handled, too without adding to a potential recycling or down-cycling process and is thus derogating its economic feasibility. Of the nonetheless collected post-consumer carpets, only nylon (mainly nylon 6) is normally reused for the new carpet production making up $47 \%$ of the recycled material. About $35 \%$ of the recycled material is reused as plastic pellets (nylon 6.6 and PP), 5\% are reused as moulded or extruded plastics produced from $\mathrm{PP}$ and as a further way of recycling $13 \%$ (PET and PP) is used as carpet padding. This shows that for carpets mainly nylon 6 is recycled and the overall recycling rate is not very high.

As there are different recycling processes for each type of plastics as well as different recycling options e.g., mechanical or chemical recycling, it is challenging to estimate the impact of the secondary plastic without comprehensive data on the material and energy input for the different recycling options. Chemical recycling includes depolymerisation followed by polymerisation resulting in virgin quality plastic [25]. Mechanical recycling, on the other hand, means only shredding, melting and extruding of the cleaned collected material. This normally results in lower quality plastic [25]. For a closed loop recycling chemical recycling is better suited as it yields in high-quality material for reuse. Nylon 6 is commonly chemically recycled, whereas nylon 6.6 is more often mechanically recycled as it is derived from two intermediates making chemical recycling more complicated [25]. In addition Nylon 6 material that is not recycled through depolymerisation does face limitations in terms of colourisation, as the initial colour is not removed, which then limits the further options for the usage of the recycling fibres (e.g., light coloured products could not be produced). And this could be initially seen as a limitation if seen from a circular economy perspective that does focus on keeping materials in the system for as long as possible with as few limitation to their utilisation. Therefor, and also because the data from the Ecoinvent database is based on averages, the analysis of this paper is focussing on chemical recycling of Nylon 6. The question,

\begin{tabular}{|l|l|}
\hline End-of-life option & Consideration in the first scenario \\
\hline Disposal via landfill & Completely considered \\
\hline Disposal via incineration & Completely considered \\
\hline $\begin{array}{l}\text { Disposal via incineration with energy } \\
\text { recuperation }\end{array}$ & Partly considered; \\
\hline Closed loop recycling & Collection and transportation of the material is considered; the incineration process itself counts as input process for energy systems \\
\hline Open loop recycling & Completely considered; \\
\hline & The recycling process is considered for the material input of the recycled material \\
\hline
\end{tabular}


if chemical or mechanical recycling of Nylon 6 materials is favourable from a circular economy perspective is, however, not part of this paper.

For a complete recycling of the carpet the carpet fibre and the backing material, as well as the filler would have to be recycled separately, as they are often made of different materials. In this analysis, only the face fibre is considered for recycling, as the typical backing consist of various bonded materials that cannot be separated and hence only be down-cycled at most. However, no comprehensive Life Cycle Inventory is available for the recycling of nylon fibres from carpets. In a US EPA documentation [23] it is also criticised that no primary, representative data is available for the closed-loop recycling process. As it is the most comprehensive, the data from Aquafil [26] (the Italian producer of nylon 6 fibres from used materials and production waste) was used for the calculation of recycled nylon 6 . The inventory is shown in Table 3. This data, in addition, considers the chemical recycling, which offers more usage options for the recycled product, e.g., in terms of colourisation as stated above.

\section{Results}

In this section, results of the footprint calculations are presented. First, an overview of the Material Footprint for a carpet from primary nylon fibres is given. Then the footprint calculation of the recycled nylon yarn is described. Finally, the three scenarios are compared with each other. Using the inventory data from the generic nylon carpet [21] and life cycle data from the Ecoinvent database [18], the Material Footprint of the carpet production from primary nylon fibres and disposal results in $9.96 \mathrm{~kg} / \mathrm{m}^{2}$ (using the data from Klinger and Savi [22] results in $9.54 \mathrm{~kg} / \mathrm{m}^{2}$ ). Regarding the data given for recycled nylon yarn in Aquafil's environmental product declaration [26] (Table 3) $0.44 \mathrm{~kg}$ of direct material input (not regarding the recycled material) is needed for the production of $1 \mathrm{~kg}$ recycled nylon yarn. This shows that the additional materials are significant when analysing the environmental impact of recycled nylon and cannot be neglected. Using this data the material footprint is estimated as being very high with $26.31 \mathrm{~kg}$ per kg of recycled nylon yarn. In Table 4 an overview of the results is given.

\begin{tabular}{|l|c|c|}
\hline $\begin{array}{l}\text { Resource given in } \\
\text { report }\end{array}$ & $\begin{array}{c}\text { Material used for } \\
\text { calculations }\end{array}$ & $\begin{array}{c}\text { Amount per kg recycled } \\
\text { Nylon yarn (Econyl®) }\end{array}$ \\
\hline PA6 recycled waste & - & $1.164 \mathrm{~kg}$ \\
\hline Limestone $\left(\mathrm{CaCO}_{3}\right)$ & Limestone & $0.097 \mathrm{~kg}$ \\
\hline Phosphorous & Phosphoric acid & $0.050 \mathrm{~kg}$ \\
\hline Sulfures & Sulfuric acid & $0.100 \mathrm{~kg}$ \\
\hline Sodium Chloride & Sodium chloride & $0.065 \mathrm{~kg}$ \\
\hline Titanium oxides & Titanium dioxide & $0.016 \mathrm{~kg}$ \\
\hline Alginate & Chemical, organic & $0.013 \mathrm{~kg}$ \\
\hline Gravel & Gravel, crushed & $0.077 \mathrm{~kg}$ \\
\hline Clay & Clay & $0.012 \mathrm{~kg}$ \\
\hline Others & Chemicals, organic & $0.008 \mathrm{~kg}$ \\
\hline Water & Tap water & $79 \mathrm{I}$ \\
\hline Electricity & Electricity & $6.5 \mathrm{kWh}$ \\
\hline
\end{tabular}

Table 3: Inventory data on the production of recycled nylon 6 fibre.
Table 4 shows that the upstream processes have the highest impact. Especially the use of titanium dioxides and other chemicals (e.g., phosphoric acid and sulphuric acid) in the upstream processes contribute to the high amount of raw materials needed. The core process of depolymerisation and fibre production only results in 9.45 $\mathrm{kg}$ Material Footprint. However, as the data is not very explicit on the specific chemicals used (Table 3), other chemicals might have been used in the actual process resulting either in a higher or lower impact on the environment than the calculated one.

\section{Comparison}

Because the identified datasets for primary production of nylon fibres and the production of recycled nylon fibres are not consistent it was necessary to adopt the recycling dataset to allow a comparison of the scenarios. The initial carpet process for carpets made from virgin nylon according to the Life Cycle Analysis of the generic nylon carpet [21] uses nylon granulate as an input while the data for recycled nylon is given in aggregated form for recycled nylon yarn. To consider recycled nylon within the defined system boundaries (Figure 1) it was necessary to extract data for the production of nylon granulate out of the recycling dataset. Therefore, the energy demand for the spinning and finishing was estimated and subtracted from the given energy demand. The filament extrusion energy of $1.7 \mathrm{kWh} / \mathrm{kg}$ and texturing energy of 1 $\mathrm{kWh} / \mathrm{kg}$ [27] was assumed and subtracted from the data for the nylon yarn, so as to have an estimation of the value of recycled nylon granulate. The result is a Material Footprint of $22.58 \mathrm{~kg} / \mathrm{kg}$ nylon granulate. The core processes, without the additional but indispensable steps like collection, shaving and grinding of post-consumer carpets, result in a much lower material footprint of per $5.72 \mathrm{~kg}$ per kg recycled nylon. As the additional process steps like collection, shaving and grinding are, however, necessary in order to be able to recycle post-consumer carpets, these processes were also included in the Material Footprint of the scenario 2 and 3 analysis. With respect to being able to compare the Material Footprints for all three scenarios the core production processes (scenario 1) or respectively the core recycling and production processes (scenario 2 and 3 ) are shown first and the Material Footprints including the additional processes are shown in brackets for scenario 2 and 3 (Table 5). Due to the high aggregation of the dataset, it was not possible to identify which specific material or process leads to the strong increase when considering collection, shaving and grinding [28] For the primary production of $1 \mathrm{~kg}$ of nylon 6 granulate $6.05 \mathrm{~kg}$ raw materials are needed. Looking at the results for recycled nylon it is not surprising that the scenario 2 and 3 results in a much higher material footprint than the base case scenario 1 .

\section{Conclusions}

The analysis of the carpet sector highlights how strongly it is still characterized by a linear system: End-of-life carpets are not seen as a potential resource but as disposable waste. A regulatory framework with incentives for closing the loop is widely lacking and under the existing framework conditions the economic incentives undermine initiatives to increase circularity. The key point of this paper is that

\begin{tabular}{|c|c|c|}
\hline Process & Description of data included & Raw material use in $\mathrm{kg} / \mathrm{per} \mathrm{kg}$ of recycled nylon yarn \\
\hline Upstream processes & $\begin{array}{l}\text { Collection of PA6 carpets, fishnets, oligomer waste; Shaving and grinding; other } \\
\text { postconsumer collection }\end{array}$ & $16.85 \mathrm{~kg} / \mathrm{kg}$ nylon yarn \\
\hline Core processes & $\begin{array}{l}\text { Waste warehouse; depolymerisation plant and secondary caprolactam production; PA6 } \\
\text { polymerization; Spinning plant; warping }\end{array}$ & $9.45 \mathrm{~kg} / \mathrm{kg}$ nylon yarn \\
\hline $\begin{array}{l}\text { Downstream } \\
\text { processes } \\
\text { Total }\end{array}$ & $\begin{array}{l}\text { Delivery } \\
\text { Upstream, core and downstream processes included }\end{array}$ & $\begin{array}{l}0.01 \mathrm{~kg} / \mathrm{kg} \text { nylon yarn } \\
26.31 \mathrm{~kg} / \mathrm{kg} \text { nylon yarn }\end{array}$ \\
\hline
\end{tabular}

Table 4: Overview of calculated resource use for upstream, core and downstream processes using data from [26]. 


\begin{tabular}{|l|c|c|c|}
\hline & $\begin{array}{c}\mathbf{1 0 0} \% \text { primary nylon fibre } \\
\text { carpet }\end{array}$ & $\mathbf{5 0 \%}$ primary nylon $\mathbf{5 0 \%}$ secondary nylon fibre carpet & $\mathbf{1 0 0 \%}$ secondary nylon fibre carpet \\
\hline $\begin{array}{l}\text { Material Footprint per } \\
\text { m2 carpet }\end{array}$ & $9.96 \mathrm{~kg}$ & $\begin{array}{c}18.05 \mathrm{~kg} \\
(9.10 \mathrm{~kg} \text { if only core processes are regarded for nylon } \\
\text { recycling) }\end{array}$ & $\begin{array}{c}\text { (8.25 } \mathrm{kg} \text { if only core processes are regarded } \\
\text { for nylon recycling) }\end{array}$ \\
\hline
\end{tabular}

Table 5: Comparison of different scenarios using the given data.

taking into account the current production and recycling technologies, an increased level of carpet recycling would lead to additional burdens for the environment. The results for the recycling of nylon 6 in the carpet industry show that recycling has a higher impact regarding the material footprint than expected. However, as the data for primary nylon 6 and recycled nylon 6 is only available in aggregated form and within different system boundaries, a direct comparison with conclusive results is not possible at the moment. The results indicate that the impact of chemical recycling, especially regarding raw materials, cannot be neglected, as high amounts of chemicals are needed for the recycling process (Table 4), which results in a high Material Footprint. Considered the weak data quality of the given datasets the following conclusion can be drawn:

- Considering the current product design of carpets the recycling process requires a large amount of chemicals. Hence actors should leverage a product design that enables an easy separation of the different materials as well as using materials which are easy to reuse or recycle. This way upstream processes of plastic recycling like e.g., separation of the different materials and cleaning might be done more resource efficiently and lead to a higher amount of material being recycled. A focus should also be set on the materials used for the production of the carpet so that more reused or recycled material can be incorporated.

- Another point that needs to be addressed with product design is the durability of carpets, as a longer durability and use by the consumer leads to less environmental impacts as this leads to carpets being exchanged less frequently. As $9.96 \mathrm{~kg}$ raw materials are used for the production of $1 \mathrm{~m} 2$ of the reference carpet, with a service life of 5 years this equals $1.99 \mathrm{~kg}$ per year, with a service life of 15 years, however, only $0.66 \mathrm{~kg}$ per year. Increasing the durability of a carpet generally also decreases the environmental impacts so that a higher durability can possibly justify a higher material use and energy consumption in the production phase.

- More research needs to be done using primary representative and comparable process data for virgin and recycled nylon fibres. This allows better assessing of the advantages and disadvantages of nylon recycling.

The results highlight that focussing on recycling alone will not achieve the environmental promises of a circular economy - it could even lead to higher resource requirements and thus higher burdens for the environment - at least as long the basic structure of carpets remains as it is. Against this background, design will have to play a key role in determining the feasibility and financial viability of carpet recycling. The first priority needs to be on increasing carpets durability and their actual use-phase or use-phases through new business models, re-use offers and technical solutions that support extended life-spans of carpets. One part of the solution could be the increased use of carpet tiles as these can be repaired, refurbishing, removed, handled and reused more easily than broadloom carpets. At the same time, the results underline that support for a more circular design of products has to be another priority, which needs support from a policy perspective. The technical feasibility of circular carpets has been demonstrated e.g., by the Dutch company Niaga that developed a new way of designing and producing pure or dual material carpets where the fibre and backing layers can easily be connected and separated due to a newly developed adhesive and the use of heat. The pure or dual material approach is prohibiting the mix of different polymers for face fibres and eliminating the need for additional materials and fillers.

Including carpets into the scope of the Ecodesign Directive could be a long-term option but based on the existing experiences with the instrument, and against the background of the reality of still linear systems, this should definitely not be the only option. Extending the physical and especially financial responsibility of producers to the end-of-life phase of their products could be an additional option for an actual change in the carpet industry. Without an effective extended producer responsibility (EPR) system, neither producers nor retailers will have any incentives other than maximising their amounts of carpets put on the market, preferably in a quality that will require users to replace them after a certain time period. If, however, the true costs of specific products - from raw material extraction to the end-of-life phase - would be incorporated into the rationale of producers (e.g., by fees for the EPR schemes based on the recyclability of materials, design changes as well as innovative take-back schemes) such an EPR system could make sense. Extended actual carpet lifespans would again be needed to go alongside such EPR-systems.

\section{References}

1. European Commission (2015) Closing the loop - An EU action plan for the Circular Economy, Communication from the Commission to the European Parliament, the Council, the European Economic and Social Committee and the Committee of the Regions COM (2015) 614/2, Brussels 2015

2. European Union (2014) Scoping study to identify potential circular economy actions, priority sectors, material flows and value chains. Publications Office of the European Union, Luxembourg: Funded under DG Environment's Framework contract for economic analysis ENV.F.1/FRA/2010/0044, 2014.

3. Wilts $H$ (2016) Germany on the road to a circular economy? Bonn: FriedrichEbert-Stiftung

4. Porter ME (1985) Competitive Advantage: Creating and Sustaining Superior Performance. NY: The Free Press.

5. Liedtke C, Katrin B, Klaus Wn, Jens T, Kathrin G, et al. (2014) Resource use in the production and consumption system : the MIPS approach. Resources 3: $544-574$.

6. Van Bergen M (2017) LIFE Closed Loop Carpet - Demonstration of separation and closed loop recycling of carpet waste into polymers for reuse in carpet production.

7. McGregor L (2013) Scotland's Zero Waste Plan \& the opportunities for carpet reuse and recycling. Carpet Recycling UK Annual Conference.

8. The Freedonia Group Inc. (2015) Carpets \& Rugs. US Industry Study with Forecasts for 2019 \& 2024

9. The Freedonia Group Inc. (2015) World Flooring and Carpet Demand

10. Vankann E (2016) Interview on carpet recycling with the head of the GUT in Aachen.

11. CRI Carpet and Rug Institut (n. d.) Cleaning of Air.

12. Recycling today (2016) California Carpet Stewardship assessment to increase in April - CARE and CalRecycle say 10 cent increase per square yard will help offset negative market developments.

13. Sanborn H, Sikorski G (2017) California Carpet Stewardship.

14. Despeisse M, Mbaye F, Ball PD, Levers A (2012) The emergence of sustainable manufacturing practices. The Management of Operations 23: 354-376. 
Citation: Wilts H, Nicolas J, Wirges M, Wiesen K (2017) Circular Economy Potential in the Carpet Industry. J Glob Econ 5: 271. doi: 10.4172/23754389.1000271

15. Hopewell J, Dvorak R, Kosior E (2009) Plastics recycling: challenges and opportunities. Philos Trans R Soc Lond B Biol Sci 364: 2115-2126.

16. Vankann E (2012) Recycling of textile floor coverings - some findings, not only based on experience.

17. Yarbrough JW (2015) State of the Carpet Industry - Responsible Production is Good Business.

18. Ecoinvent Center (2015) Ecoinvent Database Version 3.1.

19. European Commission (2016) European Life Cycle Database.

20. Mahalle L (2011) A comparative Life Cycle Assessment of Canadian hardwood flooring with alternative flooring types. FP Innovations.

21. Lippiatt B (2011) Building for Environmental and Economic Sustainability - Product Generic Nylon Carpet (BEES). Life Cycle Analysis for Building Products.
22. Klingler M, Savi D (2012) Life Cycle Assessment of Flooring. Office for Environmental Chemistry, Zurich, Documentation.

23. US EPA (2016) Documentation for Greenhouse Gas Emission and Energy Factors Used in the Waste Reduction Model (WARM) . Construction and Demolition Materials Chapter.

24. ECRA (2016) Short phone interview with the European Carpet and Rug Association.

25. Textile Exchange (2016) Material Snapshot - Recycled Nylon 6.

26. Aquafil (2011) EPD for Econyl(R) Nylon Textile Filament Yarn. Aquafil, Environmental Product Declaration.

27. Vander NMV, Patel MK, Vogtlander JG (2014) LCA benchmarking study on textiles made of cotton, polyester, nylon, acryl, or elastane. International Journal of Life Cycle Assess 19: 331-356.

28. Hoex L, COP of Niaga (2016) Niaga - the Niaga technology. 